\title{
Small-sided games in young soccer players: physical and technical variables
}

\begin{abstract}
Aim: The Small-sided games are very widespread football training exercises to improve both the physical condition and the technical abilities. The aim of the study is to evaluate and compare the internal load of the young football player using the heart rate (HR) and the perceived exertion (RPE) and to describe the type and amount of some technical skills in $3 \mathrm{vs} 3,4 \mathrm{vs} 4$ and $5 \mathrm{vs} 5$
\end{abstract}

Methods: Young soccer players.

Results: The study shows that the size with small number of players allows to have a greater internal load both in reference to the HR (3vs3: $87,2 \pm 3,3 \%$; 4 vs4: $83,8 \pm 3,8 \%$ $\mathrm{p}<0.05 ; 5 \mathrm{vs} 5: 83,7 \pm 3,6 \% \mathrm{p}<0.05$ ) both for the RPE (3vs3: 17,5 $00,7 \mathrm{AU} ; 4 \mathrm{vs} 4: 16,4 \pm 1,3$ AU $\mathrm{p}<0.05 ; 5 \mathrm{vs} 5: 15,8 \pm 1,1 \mathrm{AU} \mathrm{p}<0.001)$; while the format with large number of participants makes it possible to achieve a higher number of technical skills $(76 \%$ successful passes; $24 \%$ bad passes; $n^{\circ} 59$ tackles)

Conclusion: The results showed that the $3 \mathrm{vs} 3$ is more effective for a high-intensity aerobic training, because it generates a cardiac response that comes close to $90 \%$ of the HR max while the format with a larger number of players produced an increase in the number of specific technical skills.

Keywords: small-sided games, heart rate, young soccer players, football technical exercises, rpe
Volume I Issue I - 2017

\author{
Sannicandro Italo, ${ }^{1,2,3}$ Cofano $\mathrm{G}^{2,3}$ \\ 'Department of clinical and experimental medicine, University \\ of Foggia, Italy \\ 2Master's Degree of Preventive and Adapted Physical Activity, \\ University of Foggia, Italy \\ ${ }^{3}$ Professional Soccer Fitness Coach
}

Correspondence: Italo Sannicandro, Department of clinical and experimental medicine, University of Foggia, Italy, Tel +39.3381061646, Email italo.sannicandro@unifg.it

Received: April 13, 2017 | Published: May 03, 2017
Abbreviations: ssg-small sided games, hr-heart rate, rpe-rate of perceived exertion: $\mathrm{u} 17$ - under 17

\section{Introduction}

The Small-Sided Games (SSG) is technical exercises submitted in the form of games appropriately modified by the coaches and/or fitness coaches on the basis of sport specific training. ${ }^{1}$ These variations are done to simplify and preserve the specific characteristics of team sports practiced. ${ }^{2}$

The SSG produce numerous benefits in the soccer players; these functional benefits are described in detail in the literature: ${ }^{3,4}$ SSG are very widespread football training exercises to improve both the physical condition and the technical abilities, both in adults than in young soccer players ${ }^{5-8}$ optimizing the training time. ${ }^{9}$

The literature suggests that compared to traditional matches $11 \mathrm{vs} 11$, the SSG allow to get similar or even higher values in relation of heart rate,,$^{10,11}$ to the concentration of blood lactate, as well as to the distance covered; ${ }^{12}$ resulting, thus, very functional for the physical and technical training. ${ }^{4,7,13}$ In the youth training, it is sought training proposals that are appropriate in the physiological characteristics of young soccer player and that may increase the functional values and technical skills. ${ }^{14}$

Even the cognitive aspects relating to understanding of the game for young soccer players, also seem to depend on the field sizes, the number of players and the type of the exercises. ${ }^{15}$ In addition to motivational aspects and learning, the SSG, already from the prepubertalage, represent significant exercises for the development of technical skills, such as passing, stop, shot on goal, etc ${ }^{8,16-22}$ and physical aspects. ${ }^{8,20,23-25}$
The aim of the study is to evaluate and compare the internal load and the type and frequency of use of some technical skills in different types of SSG (3vs3, 4vs4, 5vs5) in young soccer players.

\section{Materials and methods}

The study included 10 young soccer players U17 (mean age $15,6 \pm 0,5$ years, weight: $66 \pm 7,3 \mathrm{~kg}$; height: $172 \pm 5 \mathrm{~cm})$. Written informed consent was obtained from all subjects.

HR was assessed using wireless heart rate monitors equipped with a telemetry system (Polar Electro Oy, Kempele, Finland). The 3vs3, $4 \mathrm{vs} 4$ and 5vs5 SSG was played on an $18 \times 30$ meter, $24 \times 36$ meter and $30 \times 42$ meter, respectively. ${ }^{26}$ The playing surface was composed of the latest generation of artificial turf. For the RPE the 6-20 Borg scale was used. ${ }^{27,28}$ The exercises were filmed with a camera for the next counting of technical skills. All SSG formats used a size 5 football.

The young soccer players before making the different SSG formats have followed a warm up of 15 minutes, including an aerobic activation, dynamic stretching exercises, joint mobility exercises, and running technique exercises.

The 4vs4 and 5vs5 formats were performed for 3 to 6 min while the $3 \mathrm{vs} 3$ for 3 to $4 \mathrm{~min}$. The recovery between series was passive for $90 \mathrm{sec}$ for all types of SSG examined. During the duration of the playing sessions, heart rate was constantly monitored using wireless Polar heart rate monitors and at the end of each exercise, individually, it was requested the value of RPE.

The three types of SSG were evaluated in three different days with a recovery of 24 hours between the different training sessions.

Descriptive statistics $(\mathrm{M} \pm \mathrm{SD})$ were calculated for all assessed 
variables; Student's paired t-test was used to verify the existence of statistically significant differences between the average values obtained. The significance was set at $\mathrm{p}<0.05$.

\section{Results and discussion}

The internal load analysis results show that the $3 \mathrm{vs} 3$ has produced significant higher mean values of $\%$ HR max ( $3 \mathrm{vs} 3: 87,2 \pm 3,3 \%$; $4 \mathrm{vs} 4$ : $83,8 \pm 3,8 \% \mathrm{p}<0.05 ; 5 \mathrm{vs} 5: 83, \pm 3,6 \% \mathrm{p}<0.05$ - Figure 1$)$ and significant higher values of RPE ( $3 \mathrm{vs} 3: 17,5 \pm 0,7 \mathrm{AU} ; 4 \mathrm{vs} 4: 16,4 \pm 1,3 \mathrm{AU} \mathrm{p}<0.05$; 5vs5: $15,8 \pm 1,1 \mathrm{AU} p<0.001$ - Figure 2) than other SSG type.

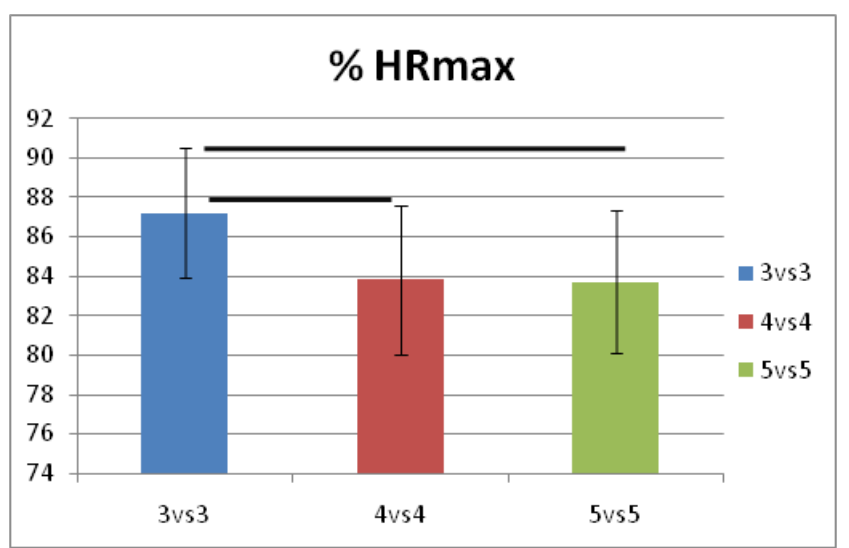

Figure I HR max percentage in different SSG.

$* \mathrm{P}<0.05,3 \mathrm{vs} 3$ versus $4 \mathrm{vs} 4$ and $5 \mathrm{vs} 5$

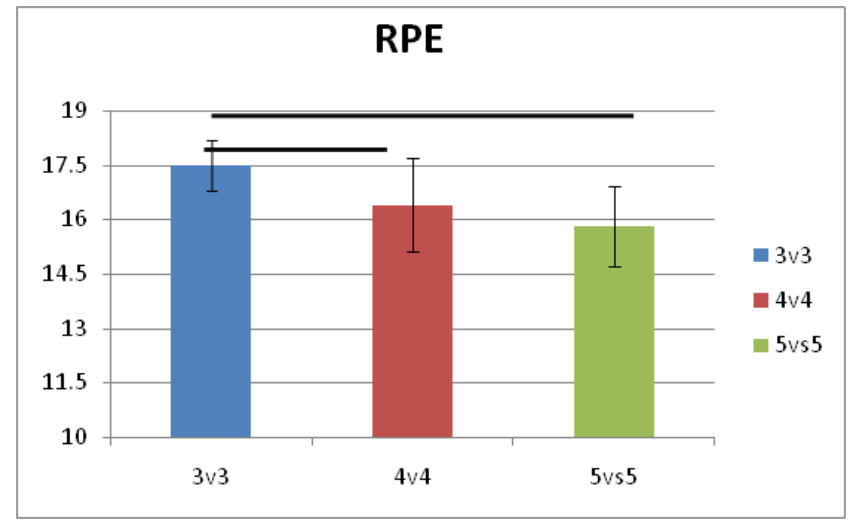

Figure 2 RPE in different SSG.

\# $\mathrm{P}<0.05,3 \mathrm{vs} 3$ versus $4 \mathrm{vs} 4$

\#\# $\mathrm{P}<0.001,3 v s 3$ versus $5 v s 5$

In the analysis of the technical aspects the $5 \mathrm{v} 5$ format allows to perform the highest percentage of successful passes $(76 \%)$, the lowest percentage of bad passes (24\%) (Figure 3) and the higher number of tackles (59) (Figure 4). The results are summarized in Table 1. The first hypothesis of the study was to evaluate and compare the internal load by HR and RPE. In the comparison between the different exercises, observing the values of HR, shows that in $3 \mathrm{vs} 3$ are detected significantly higher values $(\mathrm{p}<0.05)$ compared to $4 \mathrm{vs} 4$ and $5 \mathrm{vs} 5$, confirming literature results, or rather that the $2 \mathrm{vs} 2$ and $3 \mathrm{vs} 3$ formats are able to reach higher intensities compared to $4 \mathrm{vs} 4$ and $5 \mathrm{vs} 5$ formats. ${ }^{4,29-32}$ In the comparison between these last two SSG type there are no significant differences.

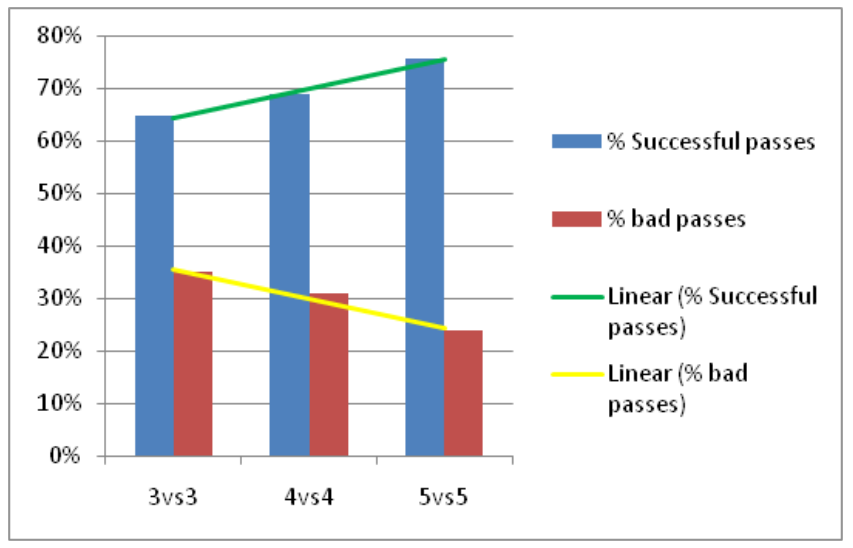

Figure 3 Percentage of successful passes and bad passes.

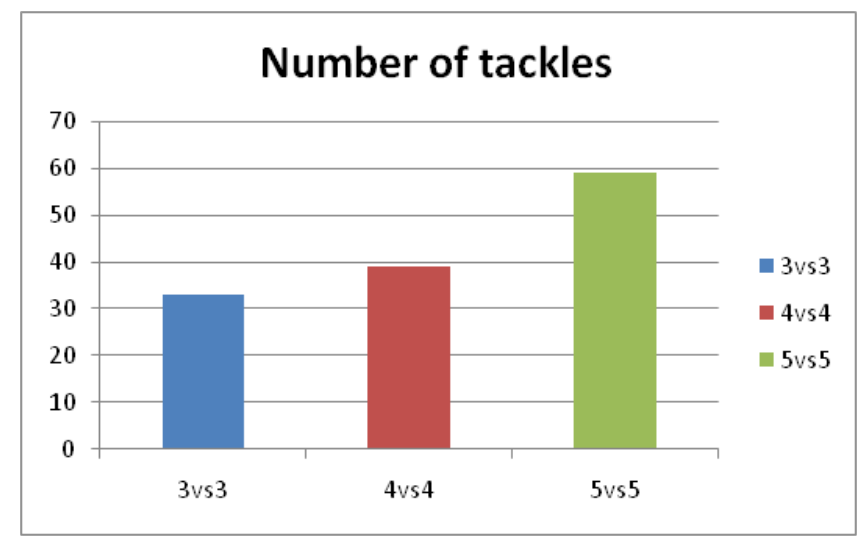

Figure 4 Number of tackles in different SSG.

Table I Analysis of the different SSG in relation to the different parameters analyzed

\begin{tabular}{llll}
\hline & $\mathbf{3}$ vs 3 & $\mathbf{4}$ sv4 & $\mathbf{5}$ vs 5 \\
\hline \% HRmax & $87,2 \pm 3,3 \%$ & $83,8 \pm 3,8 \% *$ & $83,7 \pm 3,6 \% *$ \\
RPE (6-20 AU) & $17,5 \pm 0,7$ & $16,4 \pm I, 3 \#$ & $15,8 \pm 1,1$ \\
\% successfulpasses & $65 \%$ & $69 \%$ & $76 \%$ \\
$\%$ badpasses & $35 \%$ & $31 \%$ & $24 \%$ \\
Number of tackles & 33 & 39 & 59 \\
\hline
\end{tabular}

$* \mathrm{P}<0.05,3 \mathrm{vs} 3$ versus $4 \mathrm{vs} 4$ and $5 \mathrm{vs} 5$

$\# \mathrm{P}<0.05,3 \mathrm{vs} 3$ versus $4 \mathrm{vs} 4$

$\# \#<0.001$, 3vs3 versus $5 v s 5$

The HR\% values recorded in the following study, during the exercise of $3 \mathrm{vs} 3$, stands at $87,2 \pm 3,3 \%$ of HR max, are in agreement with other studies assessing the $3 \mathrm{vs} 3$, (performed with or without the presence of goalkeepers) that have reported percentages of max HR ranging between $87 \%$ and $89 \%{ }^{16,18,25,33,34}$ This valuesare in agreement with another study that showed during an exercise conducted in $3 \mathrm{vs} 3$ "cage" modality, although with smaller subjects compared to those of this study, $\mathrm{FC}$ values equal to $88 \pm 2,7 \%$ of HR max. ${ }^{35}$

The highest and significant values of RPE, indicated in the study during the $3 \mathrm{vs} 3$, confirm that this exercise is more intense and 
wasteful compared to the other SSG, that are performed with a greater number of players and larger size. The RPE values of $3 \mathrm{vs} 3(17,5 \pm 0,7)$ are in agreement with other studies that, however, used a larger field, a greater playing time and different age subjects $(3,34)$. The RPE values revealed during the $4 \mathrm{vs} 4(16,3 \pm 1,3)$ are in agreement with other studies carried out on young players. ${ }^{33,34,36}$ The second aim of the study was to describe the type and the quantity of some technical skills in different types of SSG (3vs3, 4vs4, 5vs5).

In reference to the percentage of successful passes and bad passes, the study showed an increase percentage of successful passes when the number of players and the field sizes increased; about bad passes it was observed the opposite trend. Very probably the technical skills effectiveness was positively conditioned by the availability of a more appropriate area to formats with a greater number of players. Relatively to the parameter "tackle", instead, it was observed an increase in the number of these latter with the increase of the players involved. Very probably the high number of players may have determined an inadequate occupation of the field space game.

The results of this study are in agreement with some similar researches ${ }^{20,21}$ and disagreement with others that show that the types of SSG with a smaller number of players can lead to an increased number of technical skills, ${ }^{16,18,19}$ demonstrating the need to investigate further in this direction, because there is no agreement in the literature. ${ }^{37}$ These differences can depend by the different technical skill levels of those involved. Therefore the choice of the SSG type depends on the desired objectives: that is, if you will mostly solicit the intensity of exercise, should be preferred those with a reduced number of players and smaller fields; conversely, if you want to pursue the increase of sport-specific skills, priority must be given the SSG with a greater number of players and larger fields, confirming literature values. ${ }^{26}$

\section{Conclusion}

The study results showed that among the SSG formats observed, the $3 \mathrm{vs} 3$ is more effective for high-intensity aerobic training, because it generates a heart response of $90 \%$ of the HR max. The increase of the number of players involved in the exercises has produced an increase in the number of specific technical skills. In conclusion, it suggests the need to monitor these types of exercises to understand, describe and modulate young athletes training load.

\section{Acknowledgements}

None.

\section{Conflict of interest}

Author declares there is no conflict of interest in publishing the article.

\section{References}

1. Clemente F, Couceiro M, Martins FM, et al. The usefulness of smallsided games on soccer training. J Physic Educ Sport. 2012;12:93-102.

2. Tan CW, Chow JY, Davids K. "How does TGfU work?": examining the relationship between learning design in TGfU and a nonlinear pedagogy. Physical Education Sport Pedagogy. 2012;17(4):331-348.

3. Sampaio J, Garcia G, Macas V, et al. Heart rate and perceptual responses to $2 \times 2$ and $3 \times 3$ small-sided youth soccer games. J Sports Sci Med. 2007;6:121-122.

4. Aguiar M, Botelho G, Lago C, et al. A review on the effects of soccer small-sided games. J Hum Kinet. 2012;33:103-113.
5. Casamichana D, Castellano J, Dellal A. Influence of different training regimes on physical and physiological demands during small-sided soccer games: continuous vs. intermittent format. J Strength Cond Res. 2013;27(3):690-697.

6. Castellano J, Casamichana D, Dellal A. Influence of game format and number of players on heart rate responses and physical demands in small-sided soccer games. J Strength Cond Res. 2013;27(5):1295-1303.

7. Halouani J, Chtourou H, Gabbett T, et al. Small-sided games in team sports training: a brief review. J Strength Cond Res. 2014;28(12):3594-3618.

8. Sannicandro I, Cofano G. Small-Sided Games. Evidenze scientifiche, Esercitazioni pratiche. Milano; 2015. p. 1-159

9. Little T. Optimizing the use of soccer drills for physiological development. Strength Cond J. 2009;31:67-74.

10. Gabbett T, Mulvey M. Time-motion analysis of small-sided training games and competition in elite women soccer players. J Strength Cond Res. 2008;22(2):543-552.

11. Hill-Hass SV, Coutts A, Rowsell G, et al. Generic versus small-sided game training in soccer. Int J Sports Med. 2009;30(9):636-642.

12. Capranica L, Tessitore A, Guidetti L, et al. Heart rate and match analysis in pre-pubescent soccer players. J Sports Sci. 2001;19(6):379-384.

13. Hill-Haas SV, Dawson B, Impellizzeri FM, et al. Physiology of smallsided games training in football: a systematic review. Sports Med. 2011;41(3):199-220.

14. D'Ottavio S, Russo V. Il campo ridotto aiuta a crescere il giovane calciatore. Notiziario Settore Tecnico Figc. 1993.

15. Luhtanen P, Valovirta E, Blomquist M, et al. Game understanding and game performance in soccer and modified soccer in Finnish youth players. In: Notational Analysis of Sport Proceedings of the IV World Congress of Notational Analysis of Sport, Porto; 2001. p. 78-87

16. Platt D, Maxwell A, Horn R, et al. Physiological and technical analysis of 3v3 and 5v5 youth football matches. Insight FACA J. 2001;4(4):23-25

17. Jones S, Drust B. Physiological and technical demands of 4v4 and 8v8 games in elite youth soccer players. Kinesiology. 2007;39(2):150-156.

18. Katis A, Kellis E. Effects of small-sided games on physical conditioning and performance in young soccer players. J Sports Sci Med. 2009;8(3):374-380.

19. Kelly D, Drust B. The effect of pitch dimensions on heart rate responses and technical demands of small-sided soccer games in elite players. $J$ Sci Med Sport. 2009;12(4):475-479.

20. da Silva CD, Impellizzeri FM, Natali AJ, et al. Exercise intensity and technical demands of SSG in young brazilian soccer players: effect of number of players, maturation, and reliability. J Strength Cond Res. 2011;25(10):2746-2751.

21. Bekris E, Mylonis E, Sarakinos A, et al. Supernumerary in small sided games 3vs3 \& 4vs4. J Phys Education Sport. 2012;12(3):398-406.

22. Silva B, Garganta J, Santos R, et al. Comparing tactical behavior of soccer players in 3vs3 and 6vs6 small-sided games. J Human Kinetics. 2014;41:191-202.

23. Casamichana D, Castellano J. Time-motion, heart rate, perceptual and motor behavior demands in small-sides soccer games: effects of pitch size. J Sports Sci. 2010;28(14):1615-1623.

24. Ngo JK, Tsui MC, Smith AW, et al. The effects of man-marking on work intensity in small-sided soccer games. J Sports Sci Med. 2012;11(1):109-114.

25. Köklü Y, Sert Ö, Alemdaroğlu U, et al. Comparison of the physiological responses and time motion characteristics of young soccer players in small sided games: the effect of goalkeeper. J Strength Cond Res. 2015;29(4):964-971. 
26. Rampinini E, Impellizzeri FM, Castagna C, et al. Factors influencing physiological responses to small-sided soccer games. J Sports Sci. 2007;25(6):659-666.

27. Borg G. Physical performance and perceived exertion, Lund, Sweden Gleerup; 1962;1-63.

28. Borg G. Perceived exertion as an indicator of somatic stress. Scand $J$ Rehab Med. 1970;2(2):92-98.

29. Owen A, Twist C, Ford P. Small-sided games: The physiological and technical effect of altering field size and player number. Insight. 2004;7(2):50-53.

30. Little T, Williams AG. Measures of exercise intensity during soccer training drills with professional soccer players. J Strength Cond Res. 2007;21(2):367-371.

31. Rampinini E, Coutts AJ, Castagna C, et al. Variation in top level football match performance. Int J Sports Med. 2007;28(12):1018-1024.

32. Clemente FM, Martins FML, Mendes RS. Periodization based on Small-sided soccer games: theoretical considerations. Strength Cond J. 2014;36(5):34-43.
33. Aroso J, Rebelo AN, Gomes-Pereira J. Physiological impact of selected game-related exercises. J Sport Sci. 2004;22:522

34. Aguiar MVD, Botelho GMA, Gonçalves BSV, et al. Physiological responses and activity profiles of football small-sided games. J Strength Cond Res. 2013;27(5):1287-1294.

35. Sannicandro I, Cofano G, Rosa AR. Heart rate response comparison of young soccer players in "cage" small-sided and 8vs8 games. Journal of Physical Educational and Sport. 2016;16(4):1122-1127.

36. Brandes M, Elvers S. Elite youth soccer players physiological responses, time-motion characteristics and game performance in 4vs4 small-sided games: the influence of coach feedback. J Strength Cond Res in press. 2017.

37. Joo CH, Hwang-Bo K, Jee H. Technical and physical activities of smallsided games in young Korean soccer players. J Strength Cond Res. 2016;30(8):2164-2173. 